\title{
Midazolam Inhibits Hippocampal Long-Term Potentiation and Learning through Dual Central and Peripheral Benzodiazepine Receptor Activation and Neurosteroidogenesis
}

\author{
Kazuhiro Tokuda, ${ }^{1}$ Kazuko A. O'Dell, ${ }^{1}$ Yukitoshi Izumi, ${ }^{1}$ and Charles F. Zorumski ${ }^{1,2}$ \\ Departments of ${ }^{1}$ Psychiatry and ${ }^{2}$ Neurobiology, Washington University School of Medicine, St. Louis, Missouri 63110
}

\begin{abstract}
Benzodiazepines (BDZs) enhance $\mathrm{GABA}_{\mathrm{A}}$ receptor inhibition by direct actions on central $\mathrm{BDZ}$ receptors (CBRs). Although some BDZs also bind mitochondrial receptors [translocator protein $(18 \mathrm{kDa})(\mathrm{TSPO})$ ] and promote the synthesis of GABA-enhancing neurosteroids, the role of neurosteroids in the clinical effects of BDZs is unknown. In rat hippocampal slices, we compared midazolam, an anesthetic BDZ, with clonazepam, an anticonvulsant/anxiolytic BDZ that activates CBRs selectively. Midazolam, but not clonazepam, increased neurosteroid levels in CA1 pyramidal neurons without changing TSPO immunostaining. Midazolam, but not clonazepam, also augmented a form of spike inhibition after stimulation adjacent to the pyramidal cell layer and inhibited induction of long-term potentiation. These effects were prevented by finasteride, an inhibitor of neurosteroid synthesis, or 17PA [17-phenyl-(3 $\alpha, 5 \alpha)$-androst-16-en-3-ol], a blocker of neurosteroid effects on $\mathrm{GABA}_{\mathrm{A}}$ receptors. Moreover, the synaptic effects were mimicked by a combination of clonazepam with FGIN (2-[2-(4-fluorophenyl)-1H-indol-3-yl]- $N, N$-dihexylacetamide), a selective TSPO agonist, or a combination of clonazepam with exogenous allopregnanolone. Consistent with these in vitro results, finasteride abolished the effects of midazolam on contextual fear learning when administrated $1 \mathrm{~d}$ before midazolam injection. Thus, dual activation of CBRs and TSPO appears to result in unique actions of clinically important BDZs. Furthermore, endogenous neurosteroids are shown to be important regulators of pyramidal neuron function and synaptic plasticity.
\end{abstract}

\section{Introduction}

Benzodiazepines (BDZs) are widely used to treat anxiety, insomnia, and epilepsy, and also as intravenous anesthetics in which sedation and amnesic effects are exploited for clinical benefit (Olkkola and Ahonen, 2008). BDZs are known to depress CNS activity via central $\mathrm{BDZ}$ receptors (CBRs) that are integral components of certain $\mathrm{GABA}_{\mathrm{A}}$ receptors $\left(\mathrm{GABA}_{\mathrm{A}} \mathrm{Rs}\right.$ ) (Rudolph and Möhler, 2004). BDZs also bind intracellular receptors on mitochondria that are distinct from CBRs and referred to as "peripheral BDZ receptors" (PBRs) based on expression at non-CNS loci (Gavish et al., 1999). PBRs are now known as translocator protein (18 kDa) (TSPO) (Papadopoulos and Lecanu, 2009), reflecting their expression in the CNS and ability to bind other ligands (James et al., 2006). TSPO activation promotes cholesterol trafficking and synthesis of molecules derived from cholesterol, and regulates multiple cellular processes including apoptosis (Hirsch et al., 1998), immune function (Marino et al., 2001), and neurosteroid production (Costa et al., 1994). Neurosteroids, including $3 \alpha$-hydroxy- $5 \alpha$-prenan-20-one [allopregnanolone (AlloP)], are

Received Aug. 5, 2010; accepted Sept. 24, 2010.

This work was supported in part by National Institutes of Health Grants AA017413, MH07791, and GM47969, and The Bantly Foundation. We are grateful to Kenki Murayama who provided the initial LTP data to launch this study. We thank Doug Covey, Steve Mennerick, Joe Henry Steinbach, Alex Evers, and Gustav Akk for helpful discussions and comments. We also thank Robert Purdy for the neurosteroid antibody and helpful advice.

Correspondence should be addressed to Yukitoshi Izumi, Department of Psychiatry, Washington University School of Medicine, 660 South Euclid Avenue, St. Louis, M0 63110. E-mail: izumiy@wustl.edu.

DOI:10.1523/JNEUROSCI.4101-10.2010

Copyright $\odot 2010$ the authors $\quad 0270-6474 / 10 / 3016788-08 \$ 15.00 / 0$ generated de novo in the CNS and are potent and effective modulators of $\mathrm{GABA}_{\mathrm{A}} \mathrm{Rs}$ (Belelli and Lambert, 2005), possibly contributing to clinical effects of certain psychotropic medications (Kumar et al., 2009).

Recent studies indicate that TSPO agonists have anxiolytic effects mediated by endogenous GABAergic neurosteroids (Bitran et al., 2000; Da Settimo et al., 2008). Importantly, excitatory neurons appear to be the primary source of these neurosteroids (King et al., 2002; Agís-Balboa et al., 2006), raising the possibility that neurosteroids are important local regulators of pyramidal neuron function. We hypothesized that BDZmediated neurosteroid production may modulate pyramidal neuron firing and synaptic function. To test this, we compared midazolam, an anesthetic BDZ used clinically for its amnesic properties, and clonazepam, an anxiolytic and anticonvulsant with relatively selective actions on CBRs (Mukhin et al., 1989; Gavish et al., 1999). We compared effects on neurosteroid production, network inhibition, and synaptic plasticity in the CA1 region of rat hippocampal slices, and, in vivo, on a form of hippocampal-dependent learning. We found that midazolam, but not clonazepam, enhances a specific form of network inhibition and inhibits long-term potentiation (LTP) and learning in a neurosteroid-dependent fashion.

\section{Materials and Methods}

Animals. Protocols for animal use were approved by the Washington University Animal Studies Committee in accordance with the National Institutes of Health Guide for the Care and Use of Laboratory Animals. 
A

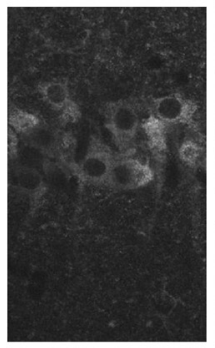

B
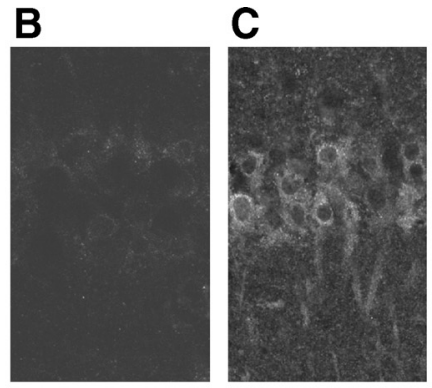

D
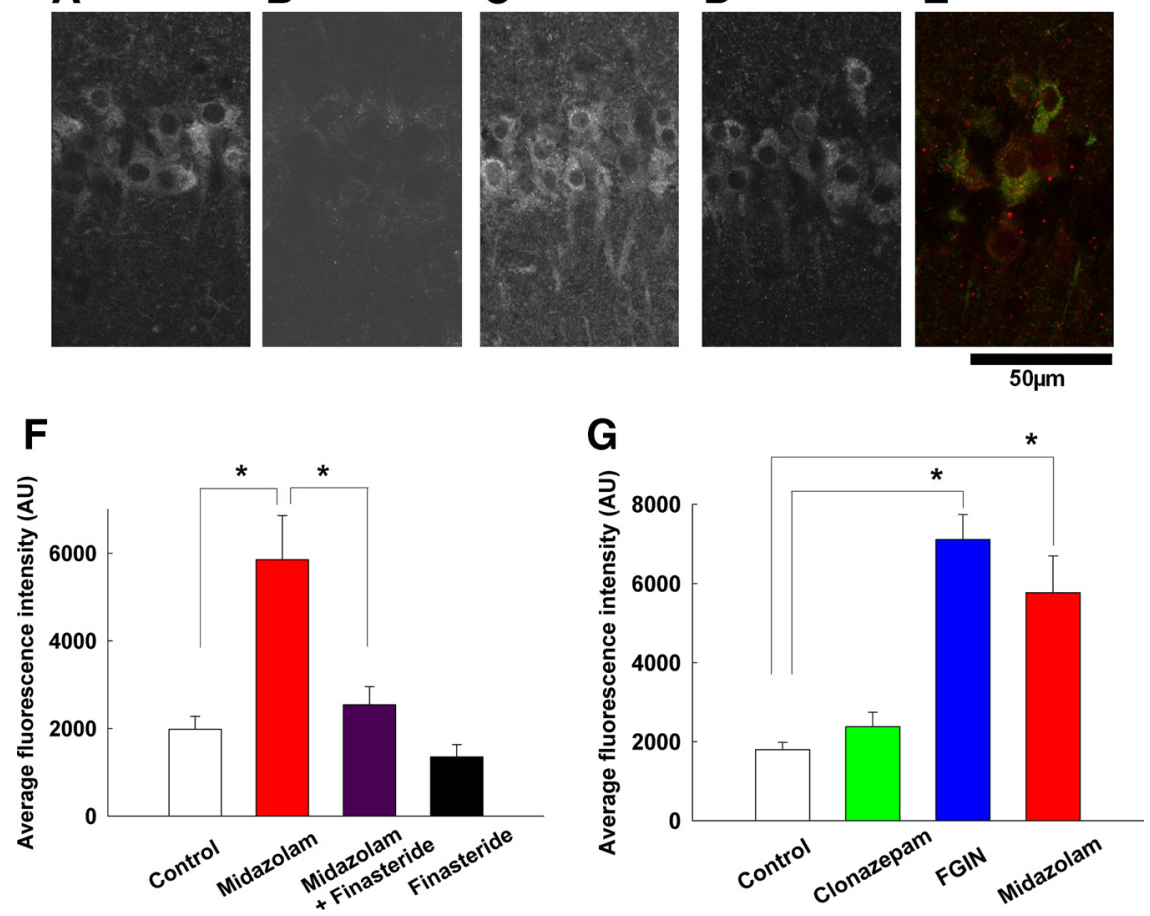

Figure 1. Localization of $5 \alpha$-reduced neurosteroids (AlloP) and TSPO in the CA1 region of rat hippocampal slices. A, Moderate AlloP staining was observed in cell bodies of pyramidal neurons in a naive slice $2 \mathrm{~h}$ after dissection. This staining was markedly attenuated by $45 \mathrm{~min}$ incubation with $1 \mu \mathrm{M}$ finasteride $(\boldsymbol{B})$ and augmented by 30 min administration of $0.1 \mu \mathrm{M}$ MDZ (C). Enhancement by MDZ was diminished by finasteride pretreatment (D). All slices are from the same hippocampus. Double staining against AlloP (green) and TSPO (red) in a naive slice shows colocalization in pyramidal neurons ( $\boldsymbol{E}$ ). $\boldsymbol{F}$, Summary of immunostaining studies shown in $\boldsymbol{A}-\boldsymbol{D}$. Fluorescence intensity (arbitrary units) in the cell body layer was augmented by MDZ and attenuated by finasteride. G, Summary of immunostaining studies comparing MDZ, clonazepam, and FGIN. Unlike $0.1 \mu \mathrm{M} \mathrm{MDZ} \mathrm{and} 1 \mu \mathrm{M} \mathrm{FGIN,5}$ $\mu \mathrm{m}$ clonazepam had no effect on AlloP immunostaining. Data are mean \pm SEM. ${ }^{*} p<0.01$ by Holm-Sidak post hoc test.

Rats were maintained on a standard $12 \mathrm{~h}$ light/dark cycle with ad libitum access to food.

Hippocampal slice preparation. Hippocampal slices were prepared from postnatal day 30-32 male Sprague Dawley rats purchased from Harlan (Zorumski et al., 1996). Rats were anesthetized with isoflurane and decapitated. Slices were cut transversely into $500 \mu \mathrm{m}$ slices using a rotary slicer in artificial CSF (ACSF) containing the following (in $\mathrm{mM}$ ): $124 \mathrm{NaCl}, 5 \mathrm{KCl}, 2 \mathrm{MgSO}_{4}, 2 \mathrm{CaCl}_{2}, 1.25 \mathrm{NaH}_{2} \mathrm{PO}_{4}, 22 \mathrm{NaHCO}_{3}, 10$ glucose, bubbled with $95 \% \mathrm{O}_{2} / 5 \% \mathrm{CO}_{2}$ at $4-6^{\circ} \mathrm{C}$. Acutely prepared slices were placed on mesh in $10 \mathrm{ml}$ beakers containing gassed ACSF and maintained for at least $1 \mathrm{~h}$ at $30^{\circ} \mathrm{C}$ before experiments.

Immunohistochemistry. Hippocampal slices used for immunohistochemistry were initially screened by electrophysiology. Using pairedpulse stimulation delivered to the Schaffer collateral (SC) pathway at an interval of $21 \mathrm{~ms}$, we selected slices showing stable paired-pulse facilitation of dendritic EPSPs and paired-pulse depression of population spikes (PSs). Selection based on physiological screening markedly diminished slice-to-slice variability in staining for $5 \alpha$-reduced neurosteroids and was consistent with the criteria used for selecting slices used for electrophysiological studies. Slices studied immunochemically were incubated with various reagents in separate $10 \mathrm{ml}$ beakers. After drug treatment, slices were fixed in $4 \%$ paraformaldehyde in PBS for $30 \mathrm{~min}$. Samples were then washed with PBS and incubated in blocking solution (1\% donkey serum/PBS) for $2 \mathrm{~h}$ at $25^{\circ} \mathrm{C}$. Slices were incubated with an antibody raised in sheep against $5 \alpha$-reduced neurosteroids diluted 1:2500 in $1 \%$ donkey serum/PBS and/or a commercial TSPO antibody diluted $1: 500$ in $1 \%$ donkey serum/PBS, for $48 \mathrm{~h}$ at $4^{\circ} \mathrm{C}$. The polyclonal antibody against $5 \alpha$-steroids has minimal cross-reactivity with other neurosteroids in rats (Bernardi et al., 1998).

After incubation with primary antibody, slices were rinsed with PBS and incubated with secondary antibody for $2 \mathrm{~h}$ at $25^{\circ} \mathrm{C}$. Alexa Fluor 488
E

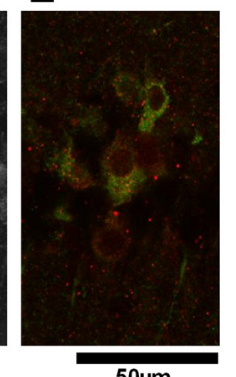

donkey anti-sheep IgG (diluted 1:500) and Alexa Fluor 647 donkey anti-rabbit IgG (diluted 1:500) were used to visualize neurosteroids and TSPO, respectively. After staining, slices were washed with PBS and mounted onto microscope slides with Fluoromount-G (Southern Biotechnology Associates).

Confocal images were obtained using a $60 \times$ objective (1.4 numerical aperture), a C1 laserscanning confocal microscope and Z-C1 software (Nikon Instruments) by a rater who was unaware of the experimental condition. All parameters were kept constant within an experiment. Digital images were analyzed and the average intensity of the tissue was measured using MetaMorph software (Universal Imaging). Data were collected from at least three independent samples.

Electrophysiology. At the time of study, slices were transferred individually to a submerged recording chamber. Experiments were performed at $30^{\circ} \mathrm{C}$ with continuous bath perfusion of ACSF at $2 \mathrm{ml} / \mathrm{min}$. Extracellular recordings were obtained from the apical dendritic layer of the CA1 region for analysis of population EPSPs and from the cell body layer for analysis of PSs. EPSPs were measured by their maximal slopes, and PSs were measured as a maximal height from the apex of the first positive peak to the most negative point of the spike.

To study proximal inhibition, we used a paired-pulse paradigm in which stimulation adjacent to the pyramidal cell layer was paired $15 \mathrm{~ms}$ later with orthodromic stimulation in stratum radiatum. Previous studies indicated that these proximal inhibitory inputs differ in their time course and pharmacology compared with distal dendritic or recurrent inhibitory inputs (Pearce, 1993; Weiner et al., 1997; Izumi et al., 2007). For these studies, orthodromic stimuli were applied at an intensity that activated $90-100 \%$ maximal PSs and the proximal stimuli were administered at an intensity that diminished baseline orthodromic PSs by $30-70 \%$. The effects of BDZ modulators, AlloP and finasteride, were determined by changes in the degree of orthodromic-evoked spike depression after proximal stimulation.

For LTP studies, evoked EPSPs were elicited with $0.1 \mathrm{~ms}$ constant current pulses through a bipolar stimulating electrode (Rhodes Medical Instruments) placed in the Schaffer collateral/commissural (stratum radiatum) pathway. EPSPs were monitored by applying single stimuli to the Schaffer collaterals every $60 \mathrm{~s}$ at an intensity sufficient to elicit halfmaximal responses. After establishing a stable baseline for at least $10 \mathrm{~min}$ and a control input-output curve, LTP was induced by applying a single $100 \mathrm{~Hz} \times 1 \mathrm{~s}$ high-frequency stimulation (HFS) using the same intensity stimulus. Input-output curves were repeated $60 \mathrm{~min}$ after HFS. For recording NMDA receptor-mediated synaptic responses (NMDAEPSPs), ACSF containing low $\mathrm{Mg}^{2+}(0.1 \mathrm{~mm})$ and high $\mathrm{Ca}^{2+}(2.5 \mathrm{~mm})$ was used to facilitate activation of NMDA receptor-gated channels. NonNMDA receptor-mediated components of synaptic response were blocked by CNQX (6-cyano-7-nitroquinoxaline-2,3-dione) (30 $\mu \mathrm{M})$. Signals were digitized and analyzed using the pCLAMP software (Molecular Devices).

Behavioral studies. Behavioral tests were conducted by an experimenter who was unaware of treatment condition. The testing apparatus consisted of two chambers equipped with a floor made of stainless-steel rods ( $4 \mathrm{~mm}$ diameter, spaced $10 \mathrm{~mm}$ apart). The grid floor in the dark compartment $(12 \times 20 \times 16 \mathrm{~cm})$ was connected to an electrical source so that a shock could be delivered when a rat entered the compartment. The adjoining safe compartment $(30 \times 20 \times 16 \mathrm{~cm})$ was illuminated with four $13 \mathrm{~W}$ lights. Light intensity in the center of the illuminated chamber 
was 1000 lux, and that in the dark chamber was $<10$ lux. On the initial day of training, rats were placed in the apparatus without turning on the light and allowed to habituate for $10 \mathrm{~min}$ in each compartment. Finasteride $(50 \mathrm{mg} / \mathrm{kg}$ suspended in Liposyn III, 30\%) or Liposyn III alone was administered by intraperitoneal injection on the same day. On the next day, each animal was placed in the illuminated compartment, and we confirmed that the rat promptly entered the dark compartment. No footshocks were given during the preexposure period. Another dose of finasteride or Liposyn III was injected 40 min before midazolam (MDZ) injection. $\mathrm{MDZ}$ ( $3 \mathrm{mg} / \mathrm{kg}$, dissolved in saline with sonication) or saline was injected 20 min before trials in which a footshock was administered when the rat entered the dark chamber. All rats were placed in the illuminated compartment and allowed to enter the dark compartment spontaneously. When rats escaped from the dark compartment, they were returned to their original home cages. On the third day, all rats were again placed in the illuminated chamber for a maximum duration of $3 \mathrm{~min}$ and monitored for the time elapsed before entering the dark compartment.

Statistical analysis. All data are expressed as mean \pm SEM. In studies using hippocampal slices, " $n$ " represents the number of slices studied in a given condition, and, unless stated otherwise, data were normalized with respect to initial control responses. Points in the graphs without error bars have an error range smaller than the symbol size. Student's $t$ test was used for comparisons between two groups. If a test of equal variance failed, the nonparametric Mann-Whitney rank sum test was applied. For multiple comparisons, ANOVA followed by post hoc Holm-Sidak test was used. Statistical analyses were performed using commercial software (SigmaStat 3.11; Systat Software). Values of $p<0.05$ were considered statistically significant.

Statistical comparisons in studies of LTP are based on analysis of input-output curves at baseline and 60 min after HFS, representing the degree of change at the half-maximal point on the input-output curves compared with baseline responses.

Materials. 2-[2-(4-Fluorophenyl)-1 $H$-indol-3-yl]- $N, N$-dihexylacetamide [FGIN-1-27 (FGIN)], flumazenil, and $\gamma$-cyclodextrin were purchased from Tocris. Finasteride and AlloP were obtained from Steraloids. ADVASEP-7 ( $\beta$-cyclodextrin sulfobutyl ether) was obtained from CyDex. All other chemicals were purchased from Sigma-Aldrich. Anti-allopregnanolone antiserum was purchased from Dr. Robert Purdy (University of California, San Diego, La Jolla, CA). TSPO antibody and TSPO blocking peptide were purchased from BioVision. Alexa Fluor 488 and Alexa Fluor 647 were purchased from Invitrogen. Liposyn III was purchased from Hospira.

\section{Results}

\section{AlloP and TSPO in the hippocampus}

We initially examined the expression of GABAergic neurosteroids in the CA1 hippocampal region using a previously characterized antibody that recognizes AlloP and other $5 \alpha$-reduced steroids (Bernardi et al., 1998; Saalmann et al., 2007). In pilot studies, we found that the intensity and distribution of neurosteroid staining correlated with baseline physiological responses. Slices exhibiting stable paired-pulse facilitation of dendritic EPSPs and paired-pulse depression of PSs, physiological signatures of slice health, showed consistent low-level slice-to-slice baseline neurosteroid staining. Thus, slices used for subsequent experiments were initially screened electrophysiologically. In naive slices, cell bodies of CA1 pyramidal neurons were diffusely positive for $5 \alpha$-reduced steroids (Fig. $1 A$ ), consistent with previous studies indicating that principal neurons are the major source of GABAergic neurosteroids (Agís-Balboa et al., 2006; Saalmann et al., 2007). Coincubations with exogenous AlloP markedly diminished this staining, confirming antibody specificity (supplemental Fig. S1C, available at www.jneurosci.org as supplemental material). Similarly, pretreatment of slices with $1 \mu \mathrm{M}$ finasteride, a $5 \alpha$ reductase inhibitor that blocks AlloP synthesis (Finn et al., 2006), mostly eliminated staining (Fig. $1 B, F$ ) as did injection of finasteride $(50 \mathrm{mg} / \mathrm{kg}$, i.p.) administered $1 \mathrm{~d}$ before dissection (supplemental Fig. S1 D, available at www.jneurosci.org as supplemental material). These latter results suggest that $5 \alpha$-reduced steroids are synthesized constitutively in the hippocampus. When naive slices were treated with $0.1 \mu \mathrm{M}$ MDZ for $30 \mathrm{~min}$, CA1 pyramidal neurons showed augmented staining (Fig. 1C), indicating that this anesthetic BDZ enhances neurosteroid production. The enhanced staining by MDZ was inhibited by pretreatment with finasteride (Fig. $1 D, F$ ). In contrast, $5 \mu \mathrm{M}$ clonazepam, a selective CBR agonist (Löscher et al., 1996), did not alter steroid staining, whereas immunostaining was en- 


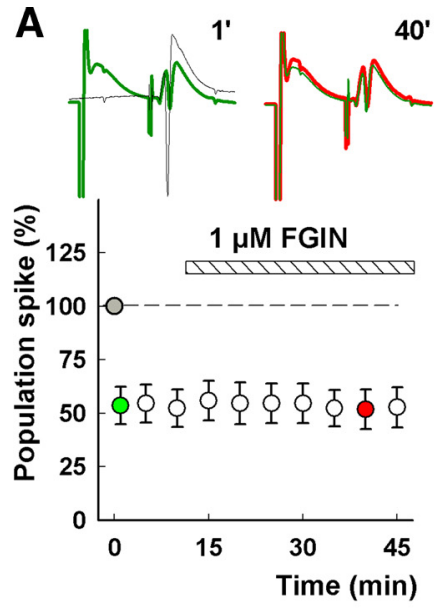

B

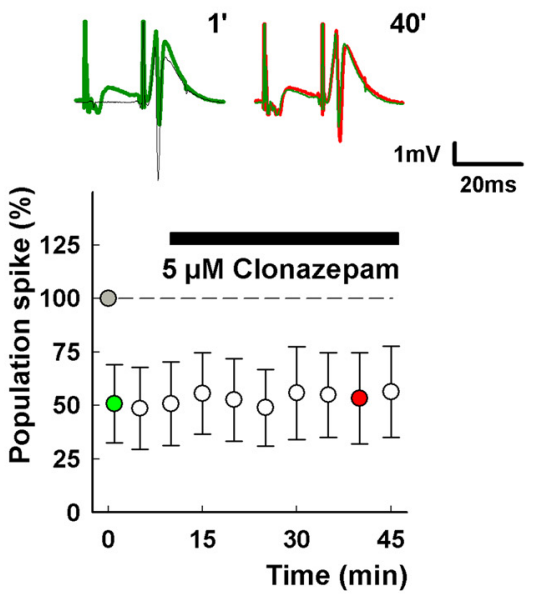

C

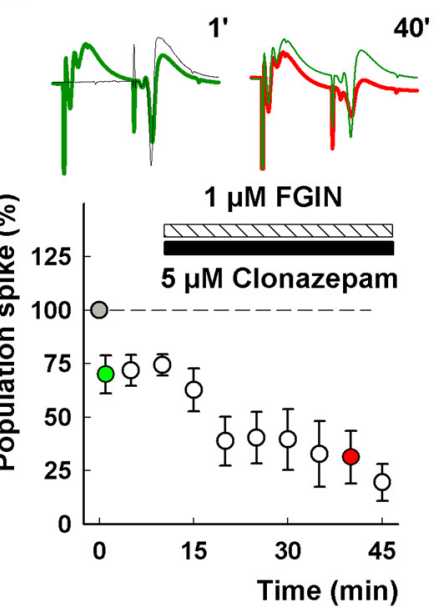

D
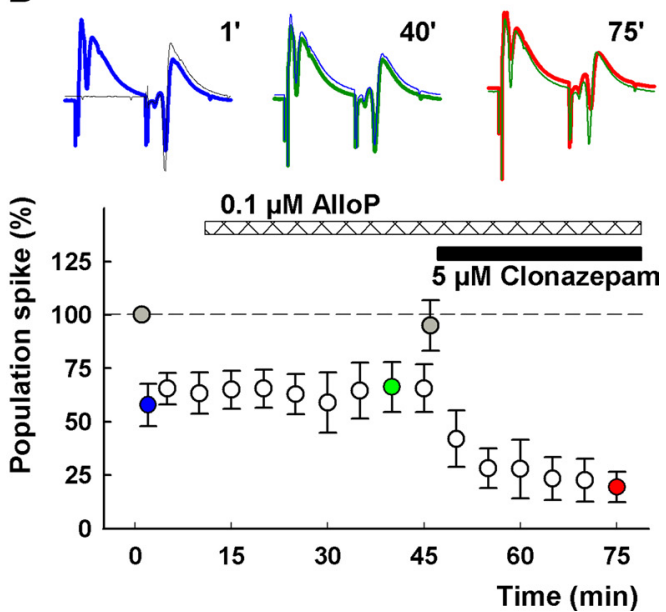

Figure 3. Effects of clonazepam on proximal inhibition. $\boldsymbol{A}$, At $1 \mu \mathrm{M}, \mathrm{FGIN}$ (hatched bar) had no effect on proximal inhibition. $\boldsymbol{B}$, Similarly at $5 \mu \mathrm{m}$, clonazepam alone had no effect on proximal inhibition. C, A combination of $1 \mu \mathrm{m}$ FGIN (hatched bar) and $5 \mu \mathrm{M}$ clonazepam (black bar) enhanced proximal inhibition. D, Although $0.1 \mu \mathrm{m}$ AlloP (cross hatched bar) had no effect on spike inhibition, a combination of AlloP and $5 \mu$ m clonazepam (black bar) augmented proximal inhibition. Raw traces above the graphs show PSs elicited by Schaffer collateral stimulation after conditioning proximal stimulation at the times indicated using the same coding as in Figure 2. Error bars indicate SEM.

hanced by FGIN, a selective TSPO agonist (Romeo et al., 1992) (Fig. 1G; supplemental Fig. S1 A, available at www.jneurosci.org as supplemental material).

Antibodies against TSPO revealed similar pyramidal neuron expression in the CA1 region, and double staining with the neurosteroid antibody showed colocalization in pyramidal neurons (Fig. $1 E$; supplemental Fig. S1 B, available at www.jneurosci.org as supplemental material). TSPO immunoreactivity was inhibited completely by coincubation with TSPO blocking peptide, confirming antibody specificity (supplemental Fig. S1 E, available at www.jneurosci.org as supplemental material). Unlike neurosteroid staining, TSPO immunoreactivity was not altered acutely by $1 \mu \mathrm{MMDZ}$ (supplemental Fig. S1 B, available at www.jneurosci.org as supplemental material). Together, these results indicate that $5 \alpha$-reduced neurosteroids are synthesized in CA1 pyramidal neurons via TSPO and that some, but not all, BDZs enhance their production.

\section{Effects of BDZs on proximal inhibition}

Because MDZ enhances neurosteroid staining in cell bodies and proximal processes of pyramidal neurons, we hypothesized that MDZ would modulate CA1 spike firing, particularly when administered with stimulation that activates inhibition at or near the cell body layer. We tested this by stimulating proximal inputs to pyramidal neurons before triggering PS firing via SC inputs (Pearce, 1993; Weiner et al., 1997; Izumi et al., 2007). SC stimulation was adjusted to evoke a maximal PS while proximal stimulation was delivered at an intensity that produced $\sim 50 \%$ depression of PS amplitude when administered $15 \mathrm{~ms}$ before the SC stimulus. At $0.1 \mu \mathrm{M}, \mathrm{MDZ}$ slowly but markedly enhanced proximal inhibition (pairedpulse PS height in control: $58.4 \pm 10.5 \%$ of baseline vs $9.3 \pm 6.0 \%$ in MDZ; $n=5 ; p<$ 0.01 by paired $t$ test) (Fig. $2 A$ ). The enhanced inhibition was reversed by $1 \mu \mathrm{M}$ picrotoxin (PTX), indicating involvement of $\mathrm{GABA}_{\mathrm{A}}$ Rs $(66.7 \pm 17.8 \%$ baseline; $p<0.05$ vs MDZ alone) (Fig. $2 A$ ).

To determine whether neurosteroids contribute to these effects, we administered finasteride before MDZ. At $1 \mu \mathrm{M}$, finasteride alone slowly attenuated proximal inhibition $(46.0 \pm 16.0 \%$ of baseline in control vs $94.0 \pm 30.5 \%$ in finasteride; $n=5 ; p<0.05$ ) (Fig. $2 B$ ). In the presence of finasteride, MDZ failed to alter PS firing ( $94.1 \pm 28.9 \%$ of baseline) (Fig. $2 B$ ). Consistent with the effects of finasteride, we also found that 17-phenyl- $(3 \alpha, 5 \alpha)$ androst-16-en-3-ol (17PA), a synthetic steroid that inhibits the effects of $5 \alpha$ reduced neurosteroids on $\mathrm{GABA}_{\mathrm{A}} \mathrm{Rs}$ (Mennerick et al., 2004), attenuated proximal inhibition of PS firing (supplemental Fig. S2A, available at www.jneurosci.org as supplemental material). These results strongly suggest that neurosteroids are involved in both the depression of PS firing resulting from proximal stimulation and MDZ-mediated enhancement of proximal inhibition.

Because neurosteroid synthesis involves TSPO, we examined the effects of FGIN on proximal inhibition. At $1 \mu \mathrm{M}$, FGIN alone failed to enhance proximal inhibition $(53.7 \pm 8.8 \%$ of baseline in control vs $52.7 \pm 9.3 \%$ in FGIN; $n=5$ ) (Fig. $3 A$ ), suggesting that, although neurosteroids are involved in this form of spike depression, activation of TSPO alone is insufficient to enhance the depression. This raises the possibility that combined effects on both TSPO and CBRs are required to produce the enhancement by MDZ. Indeed, coadministration of FGIN with $5 \mu \mathrm{M}$ clonazepam augmented proximal depression $(69.9 \pm 8.8 \%$ of baseline in control vs $19.5 \pm 8.7 \%$ in FGIN plus clonazepam; $n=5 ; p<0.05$ ) (Fig. 3C), even though clonazepam alone did not alter PS inhibition $(50.8 \pm 18.8 \%$ of baseline in control vs $56.3 \pm 1.3 \%$ in clonazepam; $n=5$ ) (Fig. $3 B$ ). Clonazepam also enhanced proximal inhibition in the presence of $0.1 \mu \mathrm{M}$ exogenous AlloP (control, $57.8 \pm 9.9 \%$, vs AlloP, $19.4 \pm 7.1 \% ; n=5 ; p<0.01$ ) (Fig. $3 D)$, a steroid concentration that does not alter PS inhibition alone $(59.0 \pm 14.1 \%)$ (Fig. $3 D)$. These results indicate that the effects of MDZ on proximal inhibition require dual activation of CBRs and TSPO. Consistent with this, flumazenil, a selective CBR antagonist, blocked the effects of MDZ but, unlike finasteride and 17PA, did not alter proximal inhibition when admin- 
istered alone (supplemental Fig. S2B, available at www.jneurosci.org as supplemental material).

\section{Effects of MDZ and neurosteroids on LTP}

Because spike firing is required for synaptic plasticity (Phillips et al., 2008), we examined the effects of MDZ on LTP induction. Administration of MDZ for 30 min before a single $100 \mathrm{~Hz} \times 1$ s HFS blocked LTP in a concentration-dependent manner (EPSP change: $151.7 \pm 4.1 \%$ of baseline in naive controls, $149.3 \pm 5.5 \%$ of baseline at $0.01 \mu \mathrm{M}$ vs $102.4 \pm 1.3 \%$ of baseline at $0.1 \mu \mathrm{M}$, measured $60 \mathrm{~min}$ after HFS; $n=5$ each) (Fig. $4 A$ ). This LTP inhibition was overcome by $1 \mu \mathrm{M}$ PTX (EPSP change: $133.5 \pm 3.6 \%$ of baseline; $n=5 ; p<0.001$ vs $0.1 \mu \mathrm{M}$ MDZ alone) (Fig. $4 B$ ) and by $1 \mu \mathrm{M}$ flumazenil (EPSP change: $142.4 \pm 6.9 \%$ of baseline; $n=5 ; p=0.008$ vs $0.1 \mu \mathrm{M} \mathrm{MDZ}$ alone) (Fig. $4 B$ ), indicating a role for $\mathrm{GABA}_{\mathrm{A}}$ Rs and CBRs. A 50-fold higher concentration of clonazepam $(5 \mu \mathrm{M})$, however, had no effect on LTP (EPSP change: $174.6 \pm$ $10.7 \%$ of baseline) (Fig. 4C), suggesting that CBRs alone are insufficient to alter synaptic plasticity. At concentrations $>5 \mu \mathrm{M}$, clonazepam significantly depressed baseline synaptic transmission, but even at $20 \mu \mathrm{M}$ did not completely block LTP induction (supplemental Fig. S3C, available at www. jneurosci.org as supplemental material).

FGIN alone also failed to inhibit LTP (EPSP change: $157.2 \pm 8.8 \%$ of baseline; $n=5$ ) (Fig. 4C), although combination of clonazepam and FGIN diminished LTP (EPSP change: $113.4 \pm 7.9 \%$ of baseline; $n=5 ; p=0.001$ vs clonazepam alone) (Fig. 4C). Thus, similar to proximal inhibition of spike firing, LTP inhibition requires both CBRs and TSPO. Also consistent with this, $1 \mu \mathrm{M}$ finasteride overcame the effects of MDZ on LTP (EPSP change: $155.0 \pm 13.0 \%$ of baseline; $n=5$; $p=0.008$ vs $0.1 \mu \mathrm{M}$ MDZ alone) (Fig. $4 D)$, as did a neurosteroid antagonist (17PA) (supplemental Fig. S3A, available at www.jneurosci.org as supplemental material), removal of endogenous neurosteroids with cyclodextrins (supplemental Fig. $\mathrm{S} 3 B$, available at www.jneurosci.org as supplemental material), and a TSPO antagonist (supplemental Fig. S4B, available at www. jneurosci.org as supplemental material) (Shu et al., 2007). Furthermore, a combination of clonazepam and FGIN failed to inhibit LTP in the presence of finasteride (EPSP change: $152.6 \pm 9.9 \%$ of baseline; $n=5 ; p=0.008$ vs $0.1 \mu \mathrm{M} \mathrm{MDZ}$ alone) (Fig. $4 C$ ), although clonazepam was effective when administered in the presence of 0.1 $\mu \mathrm{M}$ AlloP (supplemental Fig. S3D, available at www.jneurosci.org as supplemental material).

We also examined the time course of effects on LTP. At 0.1 $\mu \mathrm{M}, \mathrm{MDZ}$ inhibited LTP when administered for $30 \mathrm{~min}$ (Fig. 4A) but not $10 \mathrm{~min}$ before HFS (EPSP change: $153.1 \pm 10.6 \%$ of
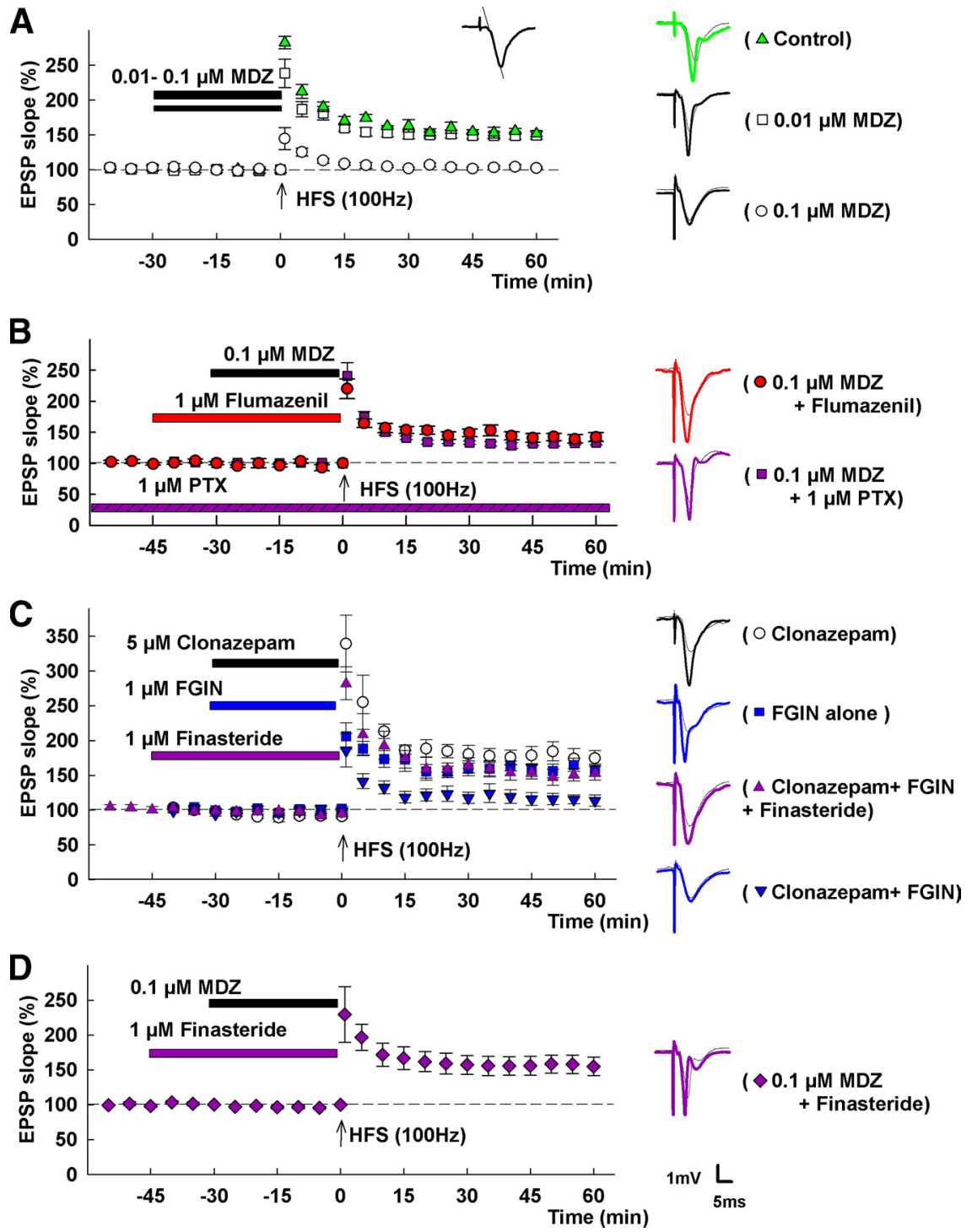

Figure 4. Effects of neurosteroid modulators on LTP. $A$, In control slices, LTP is readily induced (green triangles) by a single 100 $\mathrm{Hz} \times 1 \mathrm{~s} \mathrm{HFS} \mathrm{(arrow).} \mathrm{Thirty} \mathrm{minute} \mathrm{administration} \mathrm{of} 0.01 \mu \mathrm{M} \mathrm{MDZ}$ (thin black bar) failed to alter LTP (white squares), whereas 0.1 did not inhibit LTP (purple squares); PTX alone had no effect on LTP at this concentration. Administration of $1 \mu \mathrm{m}$ flumazenil (red bar) overcame the inhibitory effect of MDZ (red circles). C, Although $5 \mu$ m clonazepam (black bar, white circles) or $1 \mu \mathrm{m}$ FGIN alone (b) blue squares) did not alter LTP, a combination of these agents inhibited LTP (blue triangles). Finasteride (purple bar) vercame the effects of clonazepam plus FGIN (purple triangles). D, Effects of $0.1 \mu \mathrm{M} \mathrm{MDZ} \mathrm{(black} \mathrm{bar)} \mathrm{on} \mathrm{LTP} \mathrm{were} \mathrm{overcome} \mathrm{by}$ fnasteride (purple bar, purple diamonds). The traces depict EPSPs before (thin black lines) and 60 min after HFS (trace colors match symbols colors in the graphs). In all graphs, a $100 \mathrm{~Hz} \times 1$ s HFS was administered at time 0 (arrows). Error bars indicate SEM.

baseline; $n=5$ ) (Fig. $5 A$ ). We subsequently examined whether exogenous AlloP augments the inhibitory effects of $0.01 \mu \mathrm{M}$ MDZ. Although $0.01 \mu \mathrm{M} \mathrm{MDZ} \mathrm{administered} \mathrm{alone} \mathrm{for} 30 \mathrm{~min}$ did not alter LTP (Fig. 4A), $0.01 \mu \mathrm{M} \mathrm{MDZ}$ administered for $10 \mathrm{~min}$ before HFS in the presence of $0.1 \mu \mathrm{M}$ AlloP blocked LTP induction (EPSP change: $106.1 \pm 3.3 \%$ of baseline; $n=5$ ) (Fig. $5 A$ ). These observations indicate that brief exposures to low concentrations of MDZ are effective under conditions in which neurosteroids levels are increased, and that longer exposures to higher concentrations of MDZ are sufficient to promote neurosteroid synthesis and impair synaptic plasticity on their own. Administration of $0.1 \mu \mathrm{M}$ AlloP alone did not modulate LTP induction (EPSP change: $148.3 \pm 2.7 \%$ of baseline; $n=5 ; p=0.514$ vs control LTP). Furthermore, AlloP did not alter NMDA receptor- 

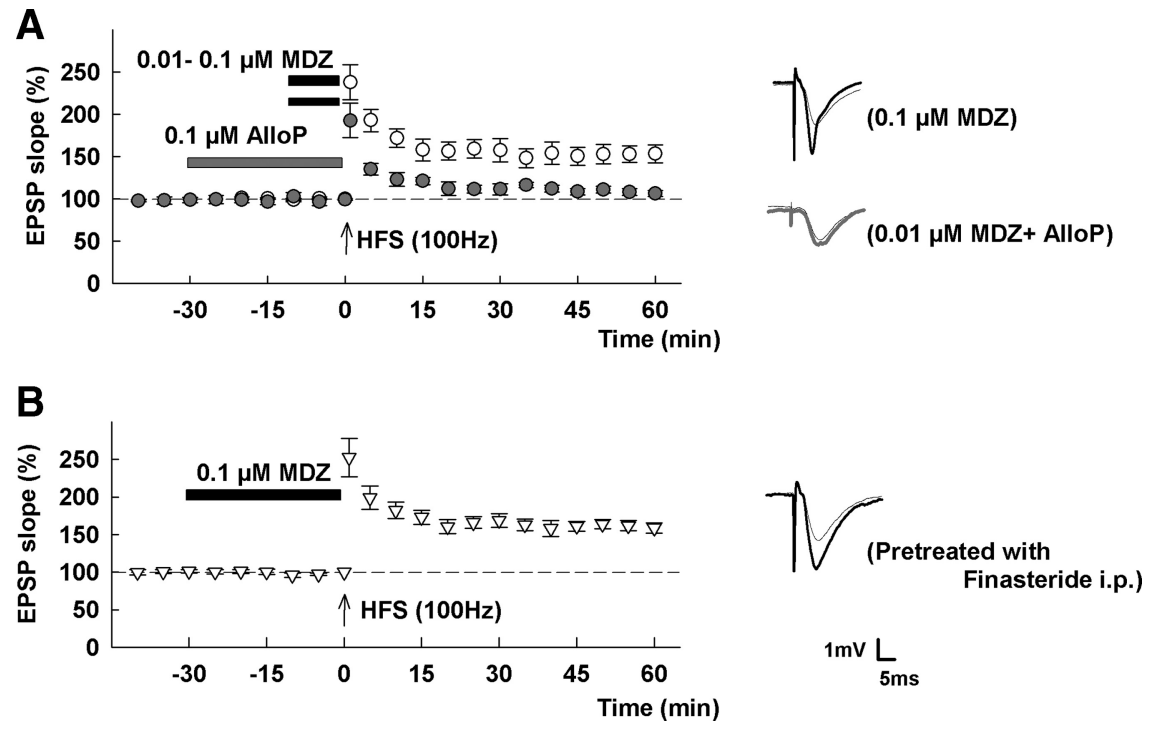

Figure 5. Time-dependent effects of $\mathrm{MDZ}$ and prevention by in vivo finasteride. $A, \mathrm{~A} 10$ min administration of $0.1 \mu \mathrm{m} M D Z$ alone (thick black bar) failed to alter LTP (white circles), although $0.01 \mu \mathrm{M} \mathrm{MDZ} \mathrm{(thin} \mathrm{black} \mathrm{bar)} \mathrm{administered} \mathrm{for} 10 \mathrm{~min}$ in the presence of AlloP (gray bar) inhibited LTP (gray circles). B, MDZ (black bar) failed to inhibit LTP in slices from rats pretreated with finasteride in vivo (50 mg/kg, i.p., $1 \mathrm{~d}$ before dissection; white triangles). Traces depict EPSPs before (thin black lines) and 60 min after HFS (trace colors match symbols colors in the graphs). In all graphs, the $100 \mathrm{~Hz} \times 1 \mathrm{~s} \mathrm{HFS} \mathrm{was} \mathrm{administered} \mathrm{at} \mathrm{time} 0$ (arrows). Error bars indicate SEM.

2nd Foot shock after MDZ

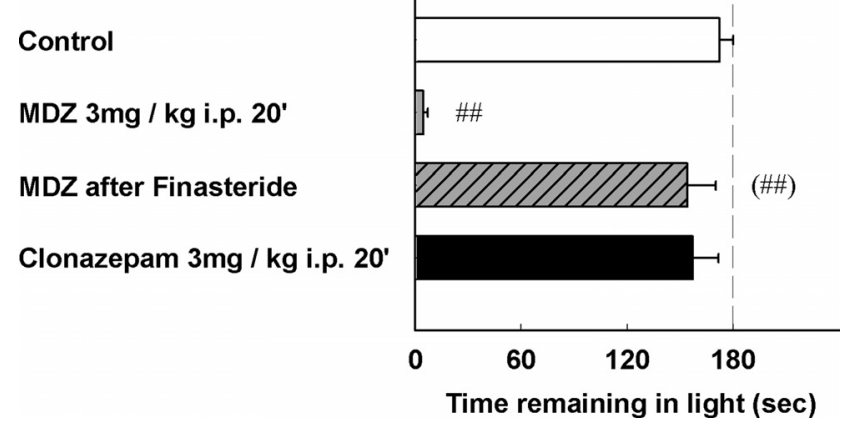

Figure 6. Neurosteroids contribute to amnesic effects of MDZ. The graph shows the average time that rats spent in the lit compartment of a two-compartment chamber $1 \mathrm{~d}$ after receiving a footshock in the dark compartment. Twenty-four hours after conditioning, control rats rarely entered the dark compartment during a 180 s observation period $(n=5)$, whereas rats treated with MDZ ( $3 \mathrm{mg} / \mathrm{kg}$, i.p.) $20 \mathrm{~min}$ before the conditioning shock readily reentered and preferred the dark chamber when tested $24 \mathrm{~h}$ later $(n=6)$. At the dose used, MDZ did not alter either the time to enter the dark compartment $[4.7 \pm 2.2 \mathrm{~s}(\mathrm{MDZ})$ vs $8.8 \pm 3.9 \mathrm{~s}]$ or the time to escape the dark compartment after shock [3.2 $\pm 0.9 \mathrm{~s}$ (MDZ) vs $3.1 \pm 0.8 \mathrm{~s}]$. Similar to controls, rats pretreated with finasteride $(50 \mathrm{mg} / \mathrm{kg})$ before MDZ treatment were reluctant to enter the dark compartment $(n=5)$. For these studies, finasteride was administered twice with an initial dose $24 \mathrm{~h}$ before conditioning and a second dose before treatment with MDZ on the day of conditioning. Rats treated with clonazepam ( $3 \mathrm{mg} / \mathrm{kg}$, i.p.) before conditioning did not differ significantly from controls $(n=6) .{ }^{\# \#} p<0.01$ by Mann-Whitney test versus control; ${ }^{(\# \#)} p<0.01$ by Mann-Whitney test versus MDZ alone. Error bars indicate SEM.

mediated synaptic responses (NMDA-EPSP change: $104.2 \pm 4.0 \%$ of baseline; $n=5 ; p=0.403$ by paired $t$ test).

\section{Effects of neurosteroids in vivo}

MDZ also failed to inhibit LTP in slices from rats treated with finasteride $(50 \mathrm{mg} / \mathrm{kg}$, i.p.) $1 \mathrm{~d}$ before dissection (EPSP change: $158.7 \pm 6.9 \%$ of baseline; $n=5 ; p=0.008$ vs $0.1 \mu \mathrm{M}$ MDZ alone) (Fig. $5 B$ ). Similarly, we found that in vivo finasteride pretreat- ment abolished the effects of MDZ on contextual fear learning. Control rats readily associated entry into a dark chamber with administration of a footshock, and avoided the dark compartment when retested $24 \mathrm{~h}$ later. At a dose that produced little behavioral sedation ( $3 \mathrm{mg} / \mathrm{kg}$, i.p., 20 min before conditioning), MDZ inhibited this learning. In contrast, rats treated with clonazepam (3 mg/kg, i.p.) showed mild behavioral sedation and fear conditioning that did not differ from controls (Fig. 6). Consistent with the LTP results, rats pretreated with finasteride $1 \mathrm{~d}$ before MDZ and conditioning had no difficulty in learning the association (Fig. 6).

\section{Discussion}

Excitatory neurons appear to play a major role in brain neurosteroid synthesis. In the hippocampus, pyramidal neurons are immunopositive for $5 \alpha$-reduced steroids (Saalmann et al., 2007) and are the primary, if not exclusive, cells that express $5 \alpha$-reductase (Agís-Balboa et al., 2006), a key synthetic enzyme, and StAR (steroidogenic acute regulatory protein), a molecular shuttle that delivers cholesterol to mitochondria for steroid synthesis (Wehrenberg et al., 2001). We found that $5 \alpha$ steroids are present constitutively in cell bodies and proximal processes of pyramidal neurons and colocalize with TSPO, a mitochondrial transporter activated by some, but not all BDZs. Although a specific TSPO agonist (FGIN) enhances steroid immunoreactivity, indicating that TSPO activation is sufficient to drive neurosteroid production, only certain BDZs promote steroid synthesis. Because previous reports indicated that TSPO is expressed in glia (Falchi et al., 2007), it is possible that steroid precursors derive from glia. However, colocalization of TSPO with $5 \alpha$-reduced steroids suggests that hippocampal neurosteroid synthesis can be principal neuron specific.

The expression of $5 \alpha$-reduced steroids in excitatory neurons suggests that these neurosteroids may be key modulators of pyramidal neuron function. We previously reported that finasteride overcomes inhibition of PS firing resulting from proximal stimulation and prevents enhancement of this inhibition by ethanol (Izumi et al., 2007). These results suggest that neurosteroids play a paracrine or perhaps autocrine role in modulating spike firing. In the present study, we found that both finasteride and an antagonist of $5 \alpha$-reduced neurosteroid actions on $\mathrm{GABA}_{\mathrm{A}} \mathrm{Rs}$ reverse proximal inhibition in naive slices. Neither agent alone modulates $\mathrm{GABA}_{\mathrm{A}} \mathrm{Rs}$, strongly suggesting that neurosteroids are key endogenous mediators of, or, at the minimum, important cofactors in this form of spike inhibition. It also appears that ambient levels of neurosteroids in pyramidal neurons may help to determine basal firing properties. Neurosteroids, however, seem to play a permissive role in modulating proximal inhibition because simply increasing steroid levels above baseline (e.g., with FGIN or MDZ in the presence of flumazenil) is insufficient to increase proximal inhibition further. Additional experiments are required to test these hypotheses. Nonetheless, the block of the effects of MDZ by either finasteride or a CBR antagonist, and the failure of FGIN alone to augment proximal inhibition, indicate that activation of both CBRs and TSPO is necessary for BDZs to 
modulate spike inhibition. Although clonazepam alone failed to augment proximal inhibition, clonazepam plus FGIN mimicked MDZ, supporting the idea that both types of BDZ receptors are important. How neurosteroids and CBRs interact is not certain but could involve changes in $\mathrm{GABA}_{\mathrm{A}} \mathrm{R}$ affinity or effects on GABA-gated channels. Additionally, the involvement of neurosteroids in the effects of $\mathrm{MDZ}$ raise the possibility that $\mathrm{GABA}_{\mathrm{A}} \mathrm{Rs}$ lacking the $\gamma 2$-subunits required for CBR actions participate in modulating proximal inhibition and LTP. In particular, extrasynaptic receptors expressing $\alpha 4$ or $\delta$ subunits receptors are insensitive to CBR agonists and could participate in the effects of neurosteroids. CBR agonist insensitivity would also be observed with $\alpha_{\mathrm{x}} \beta_{\mathrm{x}} \mathrm{GABA}_{\mathrm{A}}$ Rs while maintaining neurosteroid modulation (Rudolph and Möhler, 2004; Belelli and Lambert, 2005).

Although LTP is driven by and expressed at glutamate synapses, pyramidal neuron spiking is an important factor in LTP induction (Phillips et al., 2008). Thus, it appears that the effects of MDZ on proximal inhibition and LTP induction are related. Given the proposed role of LTP as a memory mechanism (Bliss and Collingridge, 1993; Martin et al., 2000), the factors contributing to LTP inhibition may also strongly contribute to MDZinduced amnesia, as observed in our behavioral studies. Local injection of MDZ in the hippocampus adversely affects memory acquisition, suggesting that amnesic effects involve the hippocampus (Barros et al., 1998). A recent study reported that AlloP facilitates NMDA-EPSPs and LTP in postpubertal female mice but inhibited LTP in prepubertal mice (Shen et al., 2010). In the present study, AlloP alone did not affect either NMDA-EPSPs or LTP induced by high-frequency stimulation in slices from prepubertal 30-d-old male rats. Differences in sex, pubertal status, and stimulation paradigms (theta burst stimulation vs 100 $\mathrm{Hz} \times 1 \mathrm{~s}$ tetanus) likely account for differences between these studies.

BDZs are known to disrupt human memory (Dundee and Wilson, 1980; Buffett-Jerrott and Stewart, 2002). When used to treat anxiety or insomnia, this can result in anterograde amnesia, akin to alcohol-induced "blackouts" (White, 2003). When used in anesthesia, however, memory impairment helps to prevent intraoperative awareness, a condition that can result in recollection of painful events during medical or surgical procedures (Samuelsson et al., 2007). Our results indicate that effects of BDZs on LTP require both CBRs and TSPO (supplemental Fig. S5, available at www.jneurosci.org as supplemental material); thus, only certain BDZs are likely to produce anterograde amnesia when administered alone. Clonazepam alone had no effect on either proximal inhibition or LTP. Importantly, however, when clonazepam was administered under conditions in which neurosteroid levels were acutely elevated, it had adverse effects on LTP and would be expected to have prominent effects on memory formation (supplemental Fig. S5, available at www.jneurosci.org as supplemental material). Increases in neurosteroid levels could occur during acute psychosocial stress or in the presence of other drugs such as ethanol or psychotropic medications that enhance neurosteroid production (Barbaccia, 2004; Sanna et al., 2004; Ugale et al., 2004; Verleye et al., 2005). Importantly, our results suggest that selective CBR agonists are not the sole culprits in anterograde amnesia, but rather produce deleterious effects when working in concert with elevated levels of neurosteroids. Similarly, selective TSPO agonists are unlikely to cause memory impairment alone, but will have adverse actions in the presence of mechanistically different modulators of $\mathrm{GABA}_{\mathrm{A}}$ Rs or perhaps modulators of other receptors (e.g., NMDA receptors in the case of ethanol).
Our results have implications for the design of novel neuropsychiatric medications and for augmenting or minimizing effects associated with current clinically used medications. Based on the effects of clonazepam, activation of CBRs alone appears to be sufficient to produce anticonvulsive and anxiolytic actions. Specific ligands for TSPO may share some of these effects (Rupprecht et al., 2009), whereas agents that activate both CBRs and TSPO are also expected to have amnesic and anesthetic properties. This also suggests that clinical conditions or treatments that alter neurosteroid levels can significantly modulate the effects of agents with more selective actions at other receptors, leading to novel therapeutic and adverse actions.

\section{References}

Agís-Balboa RC, Pinna G, Zhubi A, Maloku E, Veldic M, Costa E, Guidotti A (2006) Characterization of brain neurons that express enzymes mediating neurosteroid biosynthesis. Proc Natl Acad Sci U S A 103:1460214607.

Barbaccia ML (2004) Neurosteroidogenesis: relevance to neurosteroid actions in brain and modulation by psychotropic drugs. Crit Rev Neurobiol 16:67-74.

Barros DM, Izquierdo LA, Quevedo J, Rodrigues C, Madruga M, Medina JH, Izquierdo I (1998) Interaction between midazolam-induced anterograde amnesia and memory enhancement by treatments given hours later in hippocampus, entorrhinal cortex or posterior parietal cortex. Behav Pharmacol 9:163-167.

Belelli D, Lambert JJ (2005) Neurosteroids: endogenous regulators of the $\mathrm{GABA}_{\mathrm{A}}$ receptor. Nat Rev Neurosci 6:565-575.

Bernardi F, Salvestroni C, Casarosa E, Nappi RE, Lanzone A, Luisi S, Purdy RH, Petraglia F, Genazzani AR (1998) Aging is associated with changes in allopregnanolone concentrations in brain, endocrine glands and serum in male rats. Eur J Endocrinol 138:316-321.

Bitran D, Foley M, Audette D, Leslie N, Frye CA (2000) Activation of peripheral mitochondrial benzodiazepine receptors in the hippocampus stimulates allopregnanolone synthesis and produces anxiolytic-like effects in the rat. Psychopharmacology 151:64-71.

Bliss TV, Collingridge GL (1993) A synaptic model of memory: long-term potentiation in the hippocampus. Nature 361:31-39.

Buffett-Jerrott SE, Stewart SH (2002) Cognitive and sedative effects of benzodiazepine use. Curr Pharm Des 8:45-58.

Costa E, Auta J, Guidotti A, Korneyev A, Romeo E (1994) The pharmacology of neurosteroidogenesis. J Steroid Biochem Mol Biol 49:385-389.

Da Settimo F, Simorini F, Taliani S, La Motta C, Marini AM, Salerno S, Bellandi M, Novellino E, Greco G, Cosimelli B, Da Pozzo E, Costa B, Simola N, Morelli M, Martini C (2008) Anxiolytic-like effects of N, Ndialkyl-2-phenylindol-3-ylglyoxylamides by modulation of translocator protein promoting neurosteroid biosynthesis. J Med Chem 51:57985806.

Dundee JW, Wilson DB (1980) Amnesic action of midazolam. Anaesthesia 35:459-461.

Falchi AM, Battetta B, Sanna F, Piludu M, Sogos V, Serra M, Melis M, Putzolu M, Diaz G (2007) Intracellular cholesterol changes induced by translocator protein $(18 \mathrm{kDa})$ TSPO/PBR ligands. Neuropharmacology 53:318-329.

Finn DA, Beadles-Bohling AS, Beckley EH, Ford MM, Gililland KR, GorinMeyer RE, Wiren KM (2006) A new look at the 5-alpha-reductase inhibitor finasteride. CNS Drug Rev 12:53-76.

Gavish M, Bachman I, Shoukrun R, Katz Y, Veenman L, Weisinger G, Weizman A (1999) Enigma of the peripheral benzodiazepine receptor. Pharmacol Rev 51:629-650.

Hirsch T, Decaudin D, Susin SA, Marchetti P, Larochette N, Resche-Rigon M, Kroemer G (1998) PK11195, a ligand of the mitochondrial benzodiazepine receptor, facilitates the induction of apoptosis and reverses Bcl-2mediated cytoprotection. Exp Cell Res 241:426-434.

Izumi Y, Murayama K, Tokuda K, Krishnan K, Covey DF, Zorumski CF (2007) GABAergic neurosteroids mediate the effects of ethanol on longterm potentiation in rat hippocampal slices. Eur J Neurosci 26:18811888.

James ML, Selleri S, Kassiou M (2006) Development of ligands for the peripheral benzodiazepine receptor. Curr Med Chem 13:1991-2001.

King SR, Manna PR, Ishii T, Syapin PJ, Ginsberg SD, Wilson K, Walsh LP, 
Parker KL, Stocco DM, Smith RG, Lamb DJ (2002) An essential component in steroid synthesis, the steroidogenic acute regulatory protein, is expressed in discrete regions of the brain. J Neurosci 22:10613-10620.

Kumar S, Porcu P, Werner DF, Matthews DB, Diaz-Granados JL, Helfand RS, Morrow AL (2009) The role of $\mathrm{GABA}_{\mathrm{A}}$ receptors in the acute and chronic effects of ethanol: a decade of progress. Psychopharmacology (Berl) 205:529-564.

Löscher W, Rundfeldt C, Hönack D, Ebert U (1996) Long-term studies on anticonvulsant tolerance and withdrawal characteristics of benzodiazepine receptor ligands in different seizure models in mice. I. Comparison of diazepam, clonazepam, clobazam and abecarnil. J Pharmacol Exp Ther 279:561-572.

Marino F, Cattaneo S, Cosentino M, Rasini E, Di Grazia L, Fietta AM, Lecchini S, Frigo G (2001) Diazepam stimulates migration and phagocytosis of human neutrophils: possible contribution of peripheral-type benzodiazepine receptors and intracellular calcium. Pharmacology 63:42-49.

Martin SJ, Grimwood PD, Morris RG (2000) Synaptic plasticity and memory: an evaluation of the hypothesis. Annu Rev Neurosci 23:649-711.

Mennerick S, He Y, Jiang X, Manion BD, Wang M, Shute A, Benz A, Evers AS, Covey DF, Zorumski CF (2004) Selective antagonism of $5 \alpha$-reduced neurosteroid effects at $\mathrm{GABA}_{\mathrm{A}}$ receptors. Mol Pharmacol 65:1191-1197.

Mukhin AG, Papadopoulos V, Costa E, Krueger KE (1989) Mitochondrial benzodiazepine receptors regulate steroid biosynthesis. Proc Natl Acad Sci U S A 86:9813-9816.

Olkkola KT, Ahonen J (2008) Midazolam and other benzodiazepines. Handb Exp Pharmacol 182:335-360.

Papadopoulos V, Lecanu L (2009) Translocator protein (18 kDa) TSPO: an emerging therapeutic target in neurotrauma. Exp Neurol 219:53-57.

Pearce RA (1993) Physiological evidence for two distinct $\mathrm{GABA}_{\mathrm{A}}$ responses in rat hippocampus. Neuron 10:189-200.

Phillips KG, Hardingham NR, Fox K (2008) Postsynaptic action potentials are required for nitric-oxide-dependent long-term potentiation in CA1 neurons of adult GluR1 knock-out and wild-type mice. J Neurosci 28:14031-14041.

Romeo E, Auta J, Kozikowski AP, Ma D, Papadopoulos V, Puia G, Costa E, Guidotti A (1992) 2-Aryl-3-indoleacetamides (FGIN-1): a new class of potent and specific ligands for the mitochondrial DBI receptor (MDR). J Pharmacol Exp Ther 262:971-978.

Rudolph U, Möhler H (2004) Analysis of $\mathrm{GABA}_{\mathrm{A}}$ receptor function and dissection of the pharmacology of benzodiazepines and general anesthetics through mouse genetics. Annu Rev Pharmacol Toxicol 44:475-498.

Rupprecht R, Rammes G, Eser D, Baghai TC, Schüle C, Nothdurfter C, Troxler T, Gentsch C, Kalkman HO, Chaperon F, Uzunov V, McAllister KH, Bertaina-Anglade V, La Rochelle CD, Tuerck D, Floesser A, Kiese B, Schumacher M, Landgraf R, Holsboer F, et al. (2009) Translocator protein $(18 \mathrm{kD})$ as target for anxiolytics without benzodiazepine-like side effects. Science 325:490-493.

Saalmann YB, Kirkcaldie MT, Waldron S, Calford MB (2007) Cellular distribution of the $\mathrm{GABA}_{\mathrm{A}}$ receptor-modulating $3 \alpha$-hydrox, $5 \alpha$-reduced pregnane steroids in the adult rat brain. J Neuroendocrinol 19:272-284.

Samuelsson P, Brudin L, Sandin RH (2007) Late psychological symptoms after awareness among consecutively included surgical patients. Anesthesiology 106:26-32.

Sanna E, Talani G, Busonero F, Pisu MG, Purdy RH, Serra M, Biggio G (2004) Brain steroidogenesis mediates ethanol modulation of $\mathrm{GABA}_{\mathrm{A}}$ receptor activity in rat hippocampus. J Neurosci 24:6521-6530.

Shen H, Sabaliauskas N, Sherpa A, Fenton AA, Stelzer A, Aoki C, Smith SS (2010) A critical role for alpha4betadelta $G_{A B A_{A}}$ receptors in shaping learning deficits at puberty in mice. Science 327:1515-1518.

Shu HJ, Zeng CM, Wang C, Covey DF, Zorumski CF, Mennerick S (2007) Cyclodextrins sequester neuroactive steroids and differentiate mechanisms that rate limit steroid actions. Br J Pharmacol 150:164-175.

Ugale RR, Hirani K, Morelli M, Chopde CT (2004) Role of neuroactive steroid allopregnanolone in antipsychotic-like action of olanzepine in rodents. Neuropsychopharmacology 29:1597-1609.

Verleye M, Akwa Y, Liere P, Ladurelle N, Pianos A, Eychenne B, Schumacher M, Gillardin JM (2005) The anxiolytic etifoxine activates the peripheral benzodiazepine receptor and increases the neurosteroid levels in rat brain. Pharmacol Biochem Behav 82:712-720.

Wehrenberg U, Prange-Kiel J, Rune GM (2001) Steroidogenic factor-1 expression in marmoset and rat hippocampus: co-localization with StAR and aromatase. J Neurochem 76:1879-1886.

Weiner JL, Gu C, Dunwiddie TV (1997) Differential ethanol sensitivity of subpopulations of $\mathrm{GABA}_{\mathrm{A}}$ synapses onto rat hippocampal CA1 pyramidal neurons. J Neurophysiol 77:1306-1312.

White AM (2003) What happened? Alcohol, memory blackouts and the brain. Alcohol Res Health 27:186-196.

Zorumski CF, Mennerick S, Izumi Y (1996) Assessment of synaptic effects of nitric oxide in hippocampal neurons. Methods Neurosci 31:282-299. 